\title{
Loss of quality adjusted days as a trial endpoint: effect of early thrombolytic treatment in suspected myocardial infarction
}

\author{
John Rawles, Jane Light, Monika Watt on behalf of the Grampion Region Early Anistreplase \\ Trial (GREAT)
}

\begin{abstract}
Study objectives-(1) To measure the quality of life and the loss of quality adjusted days (QADS) after suspected acute myocardial infarction in patients who received thrombolytic treatment either at home or in hospital. (2) To compare the loss of QADS as a trial endpoint with the conventional endpoints of mortality and $Q$-wave infarction.

Design-Randomised double blind parallel group trial of anistreplase ( $30 \mathrm{U}$ given intravenously) and placebo given either at home
\end{abstract} or in hospital.

Setting-Rural practices in Grampian admitting patients to teaching hospitals in Aberdeen.

Patients-A total of 311 patients with suspected acute myocardial infarction and no contraindications to thrombolytic treatment seen at home within four hours of the onset of symptoms.

Measurements and main results-Loss of quality adjusted days (QADS) in the first 100 days after suspected myocardial infarction (365 QADS=1 QALY) was the main outcome measure. Compared with later administration in hospital, anistreplase at home resulted in a relative reduction of mortality of $49 \% \quad(95 \%$ confidence interval $3,95 \%$, $2 p=0 \cdot 04$ ), and a relative reduction of $26 \%$ in the proportion of survivors with infarction who had $Q$-waves $(95 \%$ CI 7,44\%, $2 \mathrm{p}=0.007)$. During the 100 day follow up, the median loss of QADS was 25 for all patients. This loss was significantly greater in those who died than in survivors (65 $v 18,2 \mathrm{p}<0.001)$, and in survivors with infarction than in survivors without infarction $(26 v 13,2 \mathrm{p}<0 \cdot 01)$. However, there was no significant difference in loss of QADS in those with infarction with or without Q-waves (29 $v 21, \mathrm{NS})$, and the median loss of QADS was not significantly different in those who had thrombolytic treatment at home or in hospital (median difference 0 , 95\% CI -5, +4 QADS).

Medicines Assessment Research Unit, University of Aberdeen, Foresterhill, Aberdeen AB9 2ZD

J Rawles

J Rawles

J Light

Correspondence to: Dr J Rawles

Accepted for publication March 1993
Conclusions-Loss of QADS had two serious limitations as an outcome measure: it was less sensitive than mortality and it failed to reflect physiological benefit. Palliative treatment with no physiological effect would have resulted in a greater gain in QADS (or QALYs) than did early thrombolytic treatment. Extreme caution is required in accepting a gain in QALYs as a valid outcome measure for health care

f Epidemiol Community Health 1993; 47: 377-381
Thrombolytic treatment is the first treatment for acute myocardial infarction that is directed at the underlying pathophysiology. Treatments previously evaluated by clinical trials have been targeted at specific, potentially fatal complications of myocardial infarction. The efficacy of these therapies may be evaluated by determining their effect on the incidence of, or the outcome from, particular complications such as ventricular fibrillation, cardiac rupture, or thromboembolism.

With thrombolytic treatments all patients might be expected to benefit, not just the small percentage who could die without it. The spectrum of possible benefits of the treatment is very wide and includes a reduction in mortality, less cardiac failure, improved exercise capacity, and an earlier return to normal activities.

Thrombolytic treatment reduces mortality, so that a small minority of patients live who would otherwise have died. By reducing infarct size, thrombolysis might also be expected to improve the quality of life for most patients who live, and who would have lived even without the treatment. The outcome measure that would be most relevant to the welfare of all patients is therefore one that combines both quantity and quality of life. ${ }^{1}$

If it were not for the adverse effects of thrombolytic therapy, particularly the liability to cause haemorrhagic stroke, its use could be advocated for all patients with evolving infarcts whatever the size. If quality of life is used as an outcome measure, adverse effects of treatment, if they impinge on the quality or quantity of life, are included in the total. The gains and losses of therapy are therefore computed in the same currency as each other, enabling the net benefit to be calculated for any group of patients. In theory, then, quality of life has much to commend it as a trial outcome measure.

In the Grampian Region Early Anistreplase Trial (GREAT), patients with suspected acute myocardial infarction were randomly allocated to receive thrombolytic therapy at home from their general practitioners, or later, in hospital. Home treatment resulted in a median time-saving of 130 minutes which was associated with lower mortality, fewer fatal and non-fatal cardiac arrests, fewer Q-wave infarcts, and better left ventricular function; there was no evidence of infarct "abortion". ${ }^{2}$ In this paper we describe the experimental use of a quality of life measure in this trial and compare its performance with that of the conventional outcome measures that were also used.

The quality of life instrument we used is derived from that of Rosser and Kind, ${ }^{3}$ and is based on 
eight objective states of disability and four subjective states of mental distress. Every combination of disability and distress has a quality of life score, whose scale runs from 0 for death, to 1 for good health without disability and distress. To derive the scores, all combinations of disability and distress were ranked in order and given a score by 70 respondents in structured interviews. The method of classifying patients' level of disability has good reproducibility, ${ }^{4}$ but the scoring system has attracted criticism because a relatively small number of respondents who were unrepresentative of the general population were used. ${ }^{5}$

In this study the Rosser-Kind disability-distress classification is used, but in conjunction with scores obtained from about 300 subjects with a wide spread of ages and social classes, more representative of the general population. ${ }^{6}$ The main difference between the old and the new scores is that the new valuation places more emphasis on distress and less on disability than the old.

The Rosser-Kind index is the basis for the calculation of quality adjusted life years (QALYs).

\section{Patients and methods}

Three hundred and eleven patients were entered into the trial-216 men and 95 women with a mean age 63 years. All patients were considered by their general practitioners to have a strong probability of acute myocardial infarction, having had typical chest pain for between 20 minutes and four hours. At home, patients were either given anistreplase (30 U intravenously) or placebo. All patients were admitted to hospital, where the alternative treatment to that received at home was given.

In hospital, the diagnosis was sought by electrocardiography and measurement of the myocardial isoenzyme of creatinine kinase (CK-MB). The diagnostic criteria used in the trial have been reported previously ${ }^{2}$ and the method of measuring quality of life has been described in a pilot study using the Rosser and Kind valuation matrix. ${ }^{1}$

The progress of patients in hospital was noted, the dates being recorded when patients were allowed out of bed, and discharged home. Before discharge patients were interviewed by a doctor

Table I Modified Rosser-Kind scale for assessing the quality of life (QOL) after admission to hospital with suspected acute myocardial infarction

\begin{tabular}{|c|c|c|c|c|c|c|}
\hline \multirow{3}{*}{\multicolumn{4}{|c|}{$\begin{array}{l}\text { State } \\
\text { Confined to bed in hospital } \\
\text { Allowed out of bed }\end{array}$}} & \multicolumn{2}{|c|}{ Disability Distress } & \multirow{3}{*}{$\begin{array}{l}Q O L \\
0.20 \\
0.40) \\
0.35 \\
0.30 \\
0.15\end{array}$} \\
\hline & & & & 7 & $\mathrm{C}$ & \\
\hline & & & & 6 & (A & \\
\hline $\begin{array}{l}\text { Discharged } \\
\text { home }\end{array}$ & $\begin{array}{l}\text { Few } \\
\text { household } \\
\text { tasks }\end{array}$ & No shopping & $\begin{array}{l}\text { Escorted } \\
\text { outings }\end{array}$ & 5 & $\begin{array}{l}\text { (A } \\
\mathrm{B} \\
\mathrm{C} \\
\mathrm{D}\end{array}$ & $\begin{array}{l}0 \cdot 45) \\
0 \cdot 40 \\
0.35 \\
0 \cdot 20\end{array}$ \\
\hline $\begin{array}{l}\text { Limited return } \\
\text { to work }\end{array}$ & $\begin{array}{l}\text { Light } \\
\text { housework }\end{array}$ & Shopping & $\begin{array}{l}\text { Unescorted } \\
\text { walks }\end{array}$ & 4 & $\begin{array}{l}\text { A } \\
\text { B } \\
\text { C } \\
\text { D }\end{array}$ & $\begin{array}{l}0 \cdot 60 \\
0 \cdot 50 \\
0 \cdot 45 \\
0 \cdot 30\end{array}$ \\
\hline $\begin{array}{l}\text { Almost full } \\
\text { work }\end{array}$ & $\begin{array}{l}\text { All except } \\
\text { heaviest } \\
\text { housework }\end{array}$ & & $\begin{array}{l}\text { Vigorous } \\
\text { walks }\end{array}$ & 3 & $\begin{array}{l}\mathrm{A} \\
\mathrm{B} \\
\mathrm{C} \\
\mathrm{D}\end{array}$ & $\begin{array}{l}0.65 \\
0.55 \\
0.50 \\
0.35\end{array}$ \\
\hline Full work & $\begin{array}{l}\text { Full } \\
\text { housework }\end{array}$ & $\begin{array}{l}\text { Social disabil } \\
\text { ie non-resum } \\
\text { of driving }\end{array}$ & tion & 2 & $\begin{array}{l}\text { A } \\
\mathrm{B} \\
\mathrm{C} \\
\mathrm{D}\end{array}$ & $\begin{array}{l}0.90 \\
0.70 \\
0.65 \\
0.45\end{array}$ \\
\hline No disability & Resumption & all activities & & 1 & $\begin{array}{l}\text { A } \\
\text { B } \\
\text { C } \\
\text { D }\end{array}$ & $\begin{array}{l}1 \cdot 00 \\
0 \cdot 90 \\
0 \cdot 85 \\
0 \cdot 50\end{array}$ \\
\hline
\end{tabular}

(JR) who had no clinical responsibility for them and did not give advice on rehabilitation. The purpose of the interview was to assess the quality of life before hospital admission, to request cooperation during follow up, and to give each patient a letter on which to record the dates when various activities were resumed after discharge from hospital. One month after admission patients were contacted (by JR), usually by telephone, and their progress was noted. Any readmissions to hospital during the 100 day follow up period, because of reinfarction or cardiac failure, for example, were logged in the same way as the initial admission. A final interview and examination took place three months after the suspected heart attack.

\section{QUALITY OF LIFE SCALE}

Table I shows the Rosser-Kind scale as adapted for use in this study. The original valuation matrix consists of eight degrees of disability (none to unconscious; 1 to 8 ) combined with four degrees of mental distress (none, mild, moderate, or severe; A to D). We have omitted the highest degree of disability, which is unconsciousness, and restricted the number of possible levels of distress at the highest levels of disability, the assumption being made that moderate distress will be experienced on admission to hospital with chest pain, and mild distress will be experienced until disability improves to level 4 or better.

The table may be used to record the dates of each stage of convalescence as the patient progresses from admission to hospital with suspected acute myocardial infarction (quality of life $7 \mathrm{C}=0 \cdot 20$ ), to restoration to full health with no disability or distress (quality of life $1 \mathrm{~A}=1 \cdot 00$ ). The same table is used to determine the quality of life score before the suspected heart attack.

\section{CALCULATION OF LOST QUALITY ADJUSTED DAYS} (QADS)

The quality of life score for each patient is plotted against the number of days since the onset of the illness. With each stage of convalescence, quality of life increases in a stepwise fashion, the assumption being made that after each improvement quality of life is maintained at the same level until the next change is reported. The area under the curve gives the number of QADS achieved in the 100 day follow up period. This number is subtracted from the product of the follow up period and the quality of life score before the heart attack, to give the number of QADS lost. Thus, if the area under the curve is 75 QADS and the premorbid quality of life score is 0.90 , then the number of QADS lost is $(0.9 \times 100)-75=15$.

\section{STATISTICAL METHODS}

Most of the quality of life data are not normally distributed, so Wilcoxon's unpaired rank sum test is used for comparison of medians. The $\chi^{2}$ test is used for comparison of proportions.

\section{Results}

MORTALITY AND Q-WAVE INFARCTION

Of 311 patients recruited, 163 were allocated anistreplase at home and 148 in hospital. Table II gives the numbers of patients who died, who had infarction confirmed, and who had Q-waves. 
Table II Number of patients, median (range) QADS lost in survivors with infarction $(M I)$, with or without $Q$-waves, in survivors without infarction, and in those who died, by place of intention to treat with thrombolytic therapy

\begin{tabular}{lllll}
\hline Group & & Home & Hospital & Combined \\
\hline Q MI & No & 59 & 66 & 125 \\
(lived) & Median & 37 & 18 & 29 \\
& (Range) & $(-30-56)$ & $(-9-57)$ & $(-30-57)$ \\
Non-Q MI & No & 54 & 28 & 82 \\
(lived) & Median & 16 & 30 & 21 \\
& (Range) & $(-28-58)$ & $(-15-54)$ & $(-28-58)$ \\
All MI & No & 113 & 94 & 207 \\
(lived) & Median & 27 & 24 & 26 \\
& (Range) & $(-30-58)$ & $(-15-57)$ & $(-30-58)$ \\
Non-MI & No & 37 & 31 & 68 \\
(lived) & Median & 14 & 9 & 13 \\
& (Range) & $(-7-49)$ & $(-12-54)$ & $(-12-54)$ \\
All who lived & No & 150 & 125 & 275 \\
& Median & 20 & 16 & 18 \\
\multirow{5}{*}{ Died } & (Range) & $(-30-58)$ & $(-15-57)$ & $(-30-58)$ \\
& No & 13 & 23 & 36 \\
& Median & 60 & 69 & 65 \\
All & (Range) & $(21-100)$ & $(19-100)$ & $(19-100)$ \\
& No & 163 & 148 & 311 \\
& Median & 24 & 25 & 25 \\
& (Range) & $(-30-100)$ & $(-15-100)$ & $(-30-100)$ \\
\hline
\end{tabular}

Home $v$ hospital NS (median difference 0 QADS, 95\% CI $-5,+4)$.

$\mathrm{Q}$-infarcts $v$ non-Q-infarcts NS (median difference 1 QADS, $95 \% \mathrm{CI}-4,+6$ ).

MI $v$ non-MI $\mathrm{p}<0.01$ (median difference 9 QADS, $95 \% \mathrm{CI}+4,+16$ ).

Died $v$ lived $\mathrm{p}<0.001$ (median difference 50 QADS, $95 \% \mathrm{CI}+41,+56$ ).

Thirty six patients died within 100 days of trial entry, 13 in the home group and 23 in the hospital group. All deaths except one were patients with acute myocardial infarction; the mortality curves are depicted in figure 1 . The curves are separate throughout the 100 day follow up period, at the end of which the mortality rate is significantly higher in the hospital than in the home group (13 of $163(8 \cdot 0 \%) v 23$ of $148(15 \cdot 5 \%) 95 \%$ CI $0 \cdot 4$, $15 \%, 2 \mathrm{p}=0 \cdot 04)$.

In those patients with confirmed infarction who lived, more had Q-waves in the home group than in the hospital group (59 of $113(52 \cdot 2 \%) v 66$ of 94 $(70 \cdot 2 \%) 95 \%$ CI $5,31 \%, 2 p=0 \cdot 007)$.

\section{QUALITY OF LIFE SCORES}

Median premorbid quality of life scores were similar in home and hospital groups $(0.91 v 0.89)$. Among survivors, the proportion of patients who had not achieved their premorbid quality of life score by 100 days was higher in those with infarction than in those without (127 of 207 $(61.4 \%)$ v 28 of $68(41.2 \%) 95 \%$ CI $7,34 \%$, $2 p=0.003)$. There was no significant difference, however, in the proportion of survivors who had not achieved their premorbid quality of life score

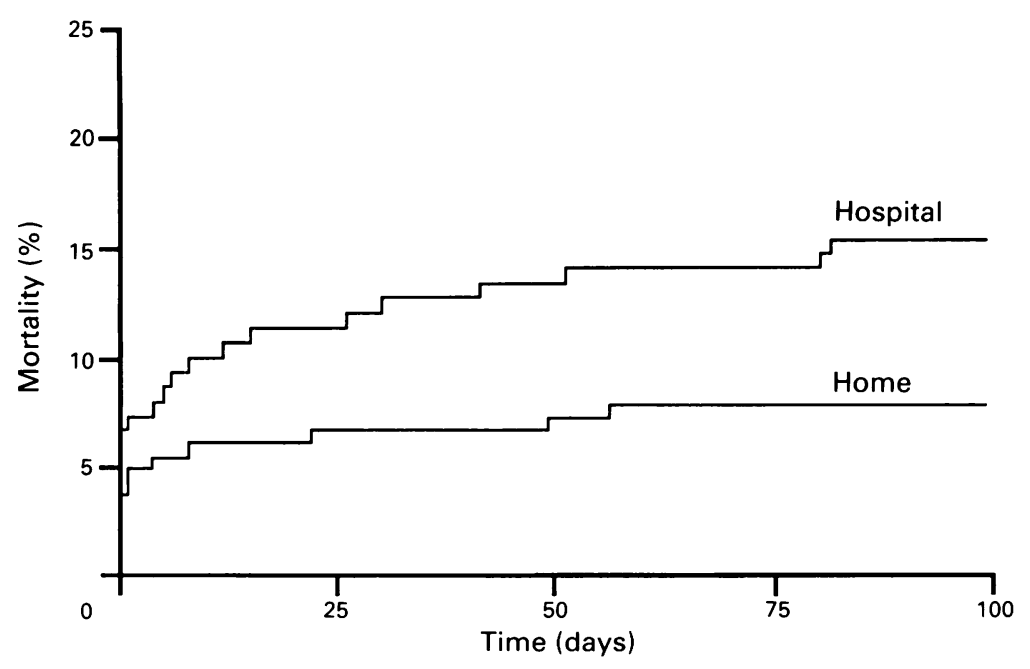

Figure 1: Cumulative mortality (\%) in home and hospital groups during the 100 day follow up period. by 100 days in the home and hospital groups $(84$ of $150(56 \cdot 0 \%) v 71$ of $125(56 \cdot 8 \%), 2 \mathrm{p}=0.90)$.

Figure 2 shows the mean quality of life scores for all patients in home and hospital groups throughout the 100 day follow up period, and figure 3 shows the scores for the survivors. For all patients the curves begin to diverge at about 30 days, but for all survivors the two curves overlap for most of their length.

LOSS OF QADS (TABLE II)

The loss of QADS was greater in those who died than in those who lived, and in survivors with infarction than in survivors without infarction. In survivors with infarction, however, there was no significant difference in the number of lost QADS between those with or without $\mathrm{Q}$-waves.

Neither in all patients combined, nor in any of the subsets, were significantly fewer QADS lost in the home group compared with the hospital group.

\section{Discussion}

The GREAT showed that patients with suspected myocardial infarction gained substantial benefits from receiving thrombolytic therapy at home at the first opportunity, rather than in hospital after a delay. Mortality was halved with home treatment, and in the survivors with confirmed infarction, full thickness Q-wave infarcts were less common; left ventricular function was also better with home than with hospital treatment. ${ }^{2}$

When the outcome of this trial was assessed by measurement of quality of life, however, no significant benefit from early treatment was seen. This could be because the instrument used to measure the quality of life is insensitive or because the benefits of early thrombolytic therapy do not translate into improved quality of life scores.

SENSITIVITY OF QUALITY OF LIFE MEASUREMENT The measurement of quality of life seems to be sensitive to changes in living circumstances. Quality of life scores were appreciably depressed at the onset of the illness, and improved progressively during the next 100 days. In the survivors, the curves overlapped for much of their extent, suggesting that the measurement of quality of life is made with considerable precision and has good reproducibility. A lower proportion of survivors with than without confirmed infarction regained their premorbid quality of life score by the end of the follow up period. Loss of QADS was greater in those who died than in those who lived, and was greater in survivors with than in survivors without confirmed myocardial infarction. All these are findings that would be expected of a sensitive measure of quality of life.

FAILURE OF QUALITY OF LIFE SCORES TO REFLECT PHYSIOLOGICAL STATUS

There was no significant difference in lost QADS in survivors with infarction with or without Qwaves. Moreover, neither in the whole group nor in any subset was there a significant difference in lost QADS in those who had thrombolytic therapy at home rather than in hospital. These results suggest that the demonstrable physiological benefits of early thrombolytic therapy-smaller 


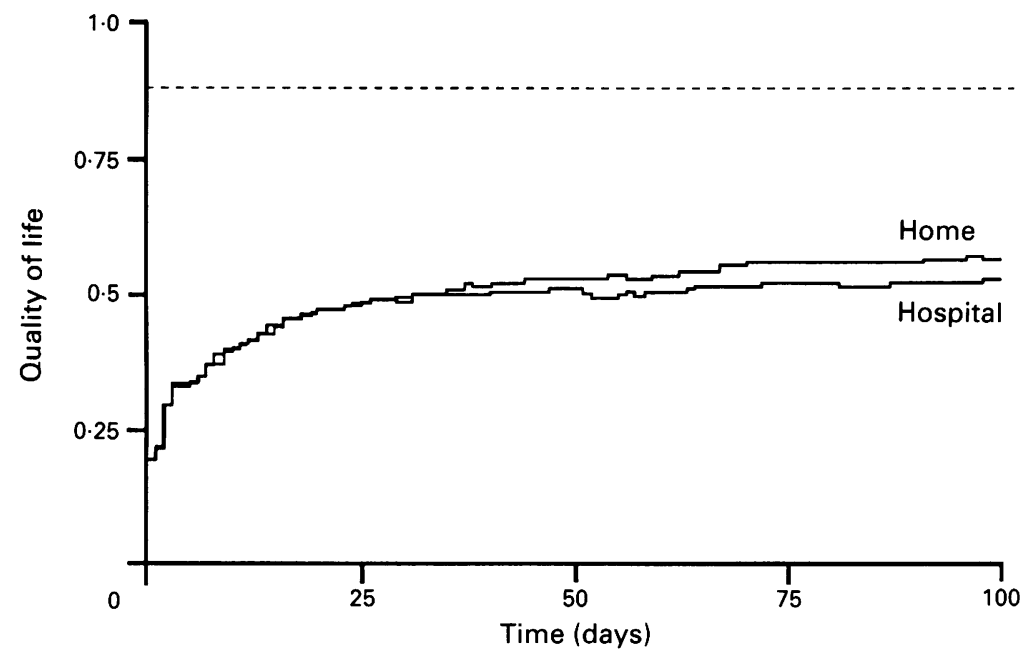

Figure 2: Mean quality of life scores in home and hospital groups during the 100 day follow up. The dashed line represents the mean premorbid quality of life.

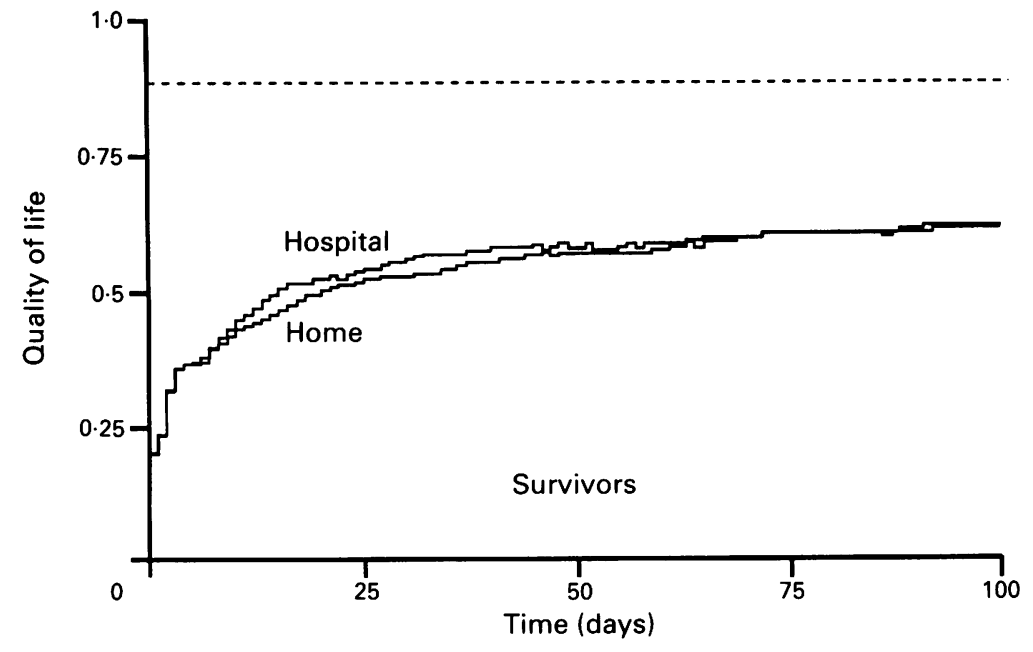

Figure 3: Mean quality of life scores in survivors in home and hospital groups during the 100 day follow up period. The dashed line represents the mean premorbid quality of life.

infarcts with better left ventricular function-are not translated into improved quality of life scores for survivors.

The failure of physiological benefit to be translated into improved quality of life scores comes about because the rate of return to normal activities after myocardial infarction is not governed by physiological capacity, but by custom and convention. In addition, the quality of life scoring system places considerable emphasis on mental distress. Thus, at any level of disability, the quality of life score is approximately halved as distress increases from none to severe. But the degree of distress occasioned by a heart attack is not closely related to the size of the infarct, and will be much the same whether the infarct is small or large, non-Q-wave or Q-wave. Hence, the quality of life score does not closely reflect physiological status.

COMPARISON OF MORTALITY AND QUALITY OF LIFE SCORE

The mortality curves for home and hospital groups are separate throughout their length, but the average quality of life scores begin to diverge only after the first month of follow up. The separation that is seen is mostly due to a difference in mortality, since there is no separation of the quality of life curves for survivors. In constructing mortality curves, death is a binary state, either present or not. Death, however, results in a variable reduction in the quality of life score, depending on the premorbid score, and a variable loss of QADS, depending on when death occurs in the follow up period. If it occurs towards the end of that period it may result in the loss of no more than the average number of QADS that are lost by survivors. On the other hand, survivors whose convalescence is particularly slow may lose as many QADS as someone who dies. The use of the quality of life scoring system cannot reflect the binary nature of death and devalues existence; the implied value of life is merely the absence of disability or distress. ${ }^{7}$ In using loss of QADS rather than mortality as an outcome measure, the distinction between those who die and those who survive becomes blurred. Hence, the quality of life score and loss of QADS are less sensitive than mortality as outcome measures.

CRITIQUE OF SHORT TERM USE OF QUALITY OF LIFE MEASUREMENT

It might be argued that we have used the quality of life scoring system to measure short term changes in a way that it was never meant to be used.

The separation of the quality of life curves seen at the end of the 100 day follow up period would continue if the follow up period were longer. Assuming no change in individual quality of life scores after 100 days, the loss of QADS by those who had died would increase with the passage of time until the loss in the hospital group would become significantly greater than the loss in the home group. With a longer follow up period, therefore, quality of life measurement would show that home treatment was preferable to hospital treatment. But the use of a longer follow up period amplifies the effect of death on loss of QADS, and sharpens the distinction between death and life, a distinction that is blurred by the use of quality of life rather than mortality as an outcome measure. The longer the follow up period, the more closely the measure behaves like mortality. But however long the follow up period, the criticism that quality of life is less sensitive than mortality as an outcome measure remains valid.

\section{EFFECT OF PALLIATIVE TREATMENT ON THE} QUALITY OF LIFE SCORE

The lower curve in figure 4 shows the mean quality of life score measured in patients in home and hospital groups combined. The upper curve, from the same patients, is calculated from quality of life scores based on disability alone, making the assumption that no distress is experienced; the curves are separate throughout their length.

The abolition of distress would result in significantly fewer QADS being lost during follow up (19 $v 25,2 \mathrm{p}<0.01)$. Thus, a hypothetical palliative treatment that relieved distress would result in fewer lost QADS than early thrombolytic therapy which attacks the underlying pathophysiology of acute myocardial infarction.

\section{IMPLICATIONS}

The quality of life scoring system described in this study is the basis for calculation of quality 


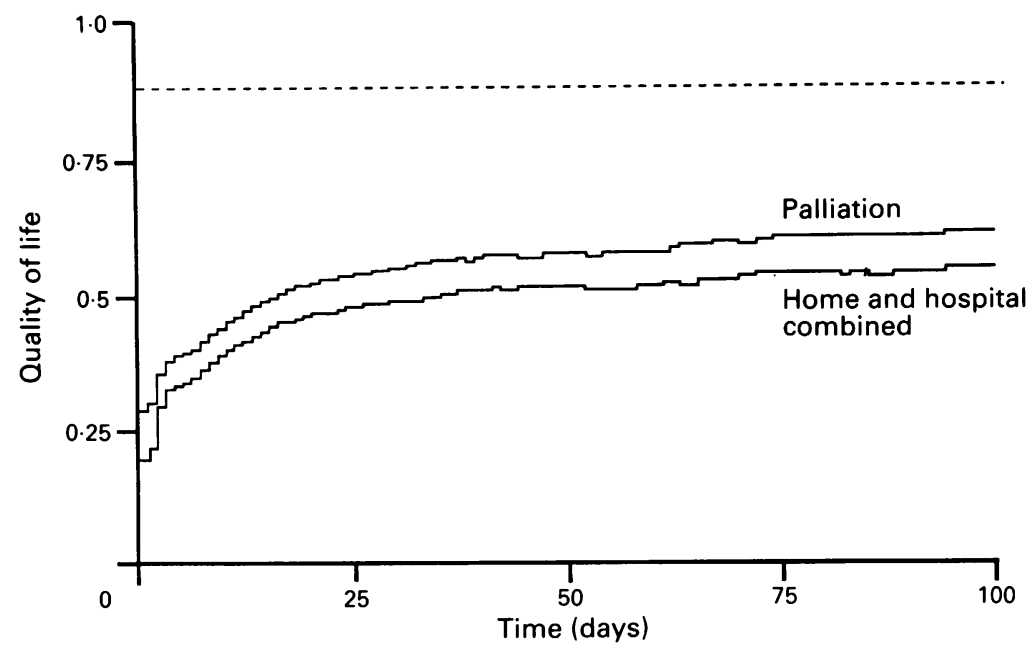

Figure 4: Mean quality of life scores in home and hospital groups combined during the 100 day follow up period (lower curve). In the upper curve the mean quality of life score for the same patients is calculated using disability as reported, but assuming the abscence of mental distress. The dashed line represents the mean premorbid quality of life score.

adjusted life years, or QALYs; 1 QALY is equivalent to 365 QADS. QALYs are calculated as the product of quantity (duration) and quality of life. The quality of life scale is so constructed that there is an equivalance between quantity and quality of life, such that one year at a quality of life of 1 ( 1 QALY) is equal in value to two years of at a quality of life of $0 \cdot 5$. Use of QALYs is considered particularly suitable for comparing the outcome of different treatments for the same condition, as in this paper.

The outcome of health care may be assessed in terms of the number of QALYs gained for a given expenditure ${ }^{8}$; allocation of resources by such value for money estimates has been advocated. ${ }^{9}$

Assuming similar costs, hypothetical palliative therapy that relieved our subjects' distress would have represented better value for money than early thrombolytic therapy that produced physiological improvement which was not reflected in a better quality of life score. This result could then have been used to support the recommendation that palliative treatment rather than thrombolytic therapy be used for myocardial infarction. It could be argued that the presence or absence of a Q-wave on the electrocardiogram has little relevance to patient welfare, while relief of distress is of greater value. But it would be diffult to argue for palliative treatment against a treatment that reduces mortality, even if, on average, the latter does not result in a significant increase in QALYs. In this study, therefore, the failure of early treatment to result in a gain in QALYs is not likely to overturn the conclusion that early thrombolytic therapy is worthwhile. But in the absence of an outcome measure other than change in QADs or QALYs, any conclusion or recommendation based solely on a quality of life score would have been unsafe.

CONCLUSIONS

As an outcome measure in a trial of thrombolytic therapy for suspected myocardial infarction, the measurement of quality of life by the Rosser-Kind index had two serious limitations-it was less sensitive than mortality and it failed to reflect physiological benefit. Moreover, since the measure is very sensitive to the occurrence of mental distress, palliative treatment with no physiological effect would have resulted in a greater gain in QALYs than did thrombolytic therapy.

Extreme caution is required in accepting gain in QALYs as a valid outcome measure for health care or as a basis for the allocation of health care resources.

We are grateful to the patients for their willingness to participate in the trial and in this study and to Mrs Joy McKnight, who so carefully collected most of the quality of life information; she was largely supported by a research grant from Grampian Health Board which is gratefully acknowledged. Professor Ian Russell kindly made helpful suggestions on the manuscript.

1 Rawles J, Light J, Watt M. The quality of life in the first 100 days after suspected acute myocardial infarction-a suitable trial endpoint? F Epidmiol Community Health 1992; 46: 612-6.

2 GREAT Group. Feasibility, safety, and efficacy of domiciliary thrombolysis by general practitioners: Grampian Region Early Anistreplase Trial (GREAT). BMf 1992; 305

3 Rosser R, Kind P. A scale of valuations of states of illness: is there a social concensus? Int $\mathcal{F}$ Epidemiol 1978; 7: 347-58.

4 Rosser RM, Watts VC. The measurement of hospital output. Int $\mathcal{F}$ Epidemiol 1972; 1: 361-8.

5 Fallowfield L. The quality of life. The missing measurement in health care. London: Souvenir Press (Education and Academic Ltd), 1990

6 Williams A, Gudex C, Kind P. QALYs: the present state of play. Health Trends 1993 (in press)

7 Rawles JM. Castigating QALYs. F Med Ethics 1989; 15 143-7.

8 Williams A. Economics of coronary artery bypass grafting $B M \mathcal{F}$ 1985; 291: 326-9.

9 Maynard A. Logic in medicine: an economic perspective. BMf 1987; 295: 1537-41. 